\title{
Identification and mapping of soybean and maize crops based on Sentinel-2 data
}

\author{
Bao She ${ }^{1,2}$, Yuying Yang ${ }^{2}$, Zhigen Zhao ${ }^{1}$, Linsheng Huang ${ }^{2}$, Dong Liang ${ }^{2}$, Dongyan Zhang ${ }^{2 *}$ \\ (1. School of Geomatics, Anhui University of Science \&Technology, Huainan 232001, Anhui, China; \\ 2. National Engineering Research Center for Agro-Ecological Big Data Analysis \& Application, Anhui University, Hefei 230601, China)
}

\begin{abstract}
Soybean and maize are important raw materials for the production of food and livestock feed. Accurate mapping of these two crops is of great significance to crop management, yield estimation, and crop-damage control. In this study, two towns in Guoyang County, Anhui Province, China, were selected as the study area, and Sentinel-2 images were adopted to map the distributions of both crops in the 2019 growing season. The data obtained on August 18 (early pod-setting stage of soybean) was determined to be the most applicable to soybean and maize mapping by means of the Jeffries-Matusita (JM) distance. Subsequently, three machine-learning algorithms, i.e., random forest (RF), support vector machine (SVM) and back-propagation neural network (BPNN) were employed and their respective performance in crop identification was evaluated with the aid of 254 ground truth plots. It appeared that RF with a Kappa of 0.83 was superior to the other two methods Furthermore, twenty candidate features containing the reflectance of ten spectral bands (spatial resolution at $10 \mathrm{~m}$ or $20 \mathrm{~m}$ ) and ten remote-sensing indices were input into the RF algorithm to conduct an important assessment. Seven features were screened out and served as the optimum subset, the mapping results of which were assessed based on the ground truth derived from the unmanned aerial vehicle (UAV) images covering six ground samples. The optimum feature-subset achieved high-accuracy crop mapping, with a reduction of data volume by $65 \%$ compared with the total twenty features, which also overrode the performance of ten spectral bands. Therefore, feature-optimization had great potential in the identification of the two crops. Generally, the findings of this study can provide a valuable reference for mapping soybean and maize in areas with a fragmented landscape of farmland and complex planting structure.
\end{abstract}

Keywords: soybean and maize, crop identification, Sentinel-2 data, machine learning, feature selection

DOI: $10.25165 /$ j.ijabe. 20201306.6183

Citation: She B, Yang Y Y, Zhao Z G, Huang L S, Liang D, Zhang D Y. Identification and mapping of soybean and maize crops based on Sentinel-2 data. Int J Agric \& Biol Eng, 2020; 13(6): 171-182.

\section{Introduction}

Soybean (Glycine max L.) and maize (Zea mays L.) are two important food crops, which are extensively grown all over the world and attract considerable attention in global food production ${ }^{[1]}$. As a high-yield crop with extremely high nutritional value, maize is known as the golden crop ${ }^{[2]}$; soybean is an important raw material of high protein food and feed ${ }^{[3]}$, and both are of great significance to national food security. China is one of the main producers of soybean and maize in the world. In 2018, the cultivated area of maize in China reached $42159 \mathrm{khm}^{2}$ (ranking first in the world), and the acreage of soybean reached $7974 \mathrm{khm}^{2}$ (ranking fifth in the world) (http://www.fao.org/ faostat/en/\#data). Meanwhile, China has to import a large amount of soybean every year as the supply is less than demand ${ }^{[4]}$. Agricultural departments have continuously implemented policies to promote soybean production in recent years and strived to expand the acreage of soybean cultivation. Therefore, obtaining information on the spatial distributions of

Received date: $2020-09-25 \quad$ Accepted date: $2020-10-27$

Biographies: Bao She, $\mathrm{PhD}$, Lecture, research interest: agricultural remote sensing, Email: shebao518@aust.edu.cn; Yuying Yang, Master candidate, research interest: remote sensing information processing, Email: p17201110@stu.ahu.edu.cn; Zhigen Zhao, PhD, Professor, research interest: ground-feature detection, Email: zhgzhao@aust.edu.cn; Linsheng Huang, PhD, Professor, research interest: remote sensing information processing, E-mail: linsheng0808@ahu.edu.cn; Dong Liang, PhD, Professor, research interest: machine vision, Email: dliang@ahu.edu.cn.

*Corresponding author: Dongyan Zhang, PhD, Professor, research interest: agricultural remote sensing and information technology. Anhui University, Hefei 230601, China. Tel: +86-551-63861275, Email: zhangdy@ahu.edu.cn. soybean and maize in a timely and accurate manner is essential for the government to guide agricultural production and formulate agricultural policies ${ }^{[5]}$. Traditional methods of manual field investigation to estimate the acreage of soybean and maize usually consume lots of time, labor, and resources with low efficiency and strong subjectivity, and the results of the investigation also lack spatial distribution information ${ }^{[6]}$. Remote sensing has the potential of large-scale crop identification and mapping in the field of agriculture, providing a timely, efficient, low-cost and objective way to monitor large areas simultaneously ${ }^{[7]}$.

Mapping of soybean and maize by using remote-sensing data is primarily based on the unique signatures of both crops in terms of spectrum and crop phenology. The majority of previous studies have explored the potential of spectral characteristics in identifying soybean and maize. Utilizing single time-phase Landsat- 8 OLI data, Wang et al ${ }^{[8,9]}$ found that RF had great advantages of accurate identification of soybean and maize, in addition, the importance of shortwave-infrared and near-infrared bands was highlighted. Furthermore, based on time-series Sentinel-2 images, the crucial role of short-wave infrared bands in the identification of soybean and maize was also confirmed in the work by Yin et al. ${ }^{[10]}$. Red-edge range refers to the bands with central wavelength ranging from $670 \mathrm{~nm}$ to $780 \mathrm{~nm}$, which is generally considered to be very effective in vegetation monitoring. Sidike et al. ${ }^{[1]}$ utilized WorldView-3 data to map the heterogeneous agricultural landscape and the red-edge band (705 nm-745 nm) was considered to be the most important feature that affected classification accuracy. Microwave remote sensing is sensitive to certain surface properties and works under all weather conditions, which can be used for crop 
identification especially in the case of limited cloud-free optical images. To obtain a reliable maize-cultivated area under the condition of smallholder farming with tremendous heterogeneity, Jin et al. ${ }^{[12]}$ adopted microwave data (Sentinel-1 radar data) in addition to the image of traditional Sentinel-2 optical sensor and pointed out that the backscatter metrics could improve the identification accuracy of maize.

Vegetation index (VI) also plays an important role in soybean and maize identification in addition to the reflectance of spectral bands. Souza et al. ${ }^{[13]}$ successfully mapped the distributions of soybean and maize in Paraná, Brazil by using VIs generated from Moderate Resolution Imaging Spectroradiometer (MODIS) data and found that the wide dynamic range vegetation index (WDRVI) and enhanced vegetation index (EVI) behaved better than normalized difference vegetation index (NDVI). Silva et al. ${ }^{[14]}$ proposed a new VI termed as perpendicular crop enhancement index (PCEI) with the support of time-series MODIS data and used it to participate in the construction of a decision-tree model to extract soybean cultivated area. Huang et al. ${ }^{[6]}$ evaluated the performance of different VIs derived from multi-temporal GF-1 WFV data to map soybean and maize by using maximum likelihood, support vector machine (SVM), and random forest (RF) classifiers and the results showed that RF classifier combined with NDVI, normalized difference water index (NDWI), and WDRVI as the input had the best performance. Considering the existence of the mixed-pixel effect, Li et al. ${ }^{[15]}$ applied the linear spectral unmixing model to estimate the soybean-planting area in Lishu County, Northeast China based on TM data and the accuracy reached up to $92 \%$.

Crop phenology derived from multi-temporal images has great potential in crop identification, and crop phenology metrics can be generated from e.g., MODIS NDVI/EVI time-series data ${ }^{[16-18]}$. Liu et al. ${ }^{[19]}$ applied thirty-eight phenology metrics calculated from MCD43A4 product to map soybean and maize and noticed that the date-related metrics were the most important variables. Chen et al. ${ }^{[20]}$ concluded that under the condition of high spatial heterogeneity, eleven key phenological parameters derived from time-series MODIS-NDVI data could be used for crop mapping. However, it is difficult to guarantee the continuity of time-series data due to adverse factors such as cloud cover, which brings more challenges to phenological-metrics extraction. To address this problem, some studies have combined spectral signatures with phenological metrics to identify soybean and maize. To date, the combination of phenology-related and spectral metrics has been proved to be very effective to achieve satisfactory accuracy in soybean and maize mapping ${ }^{[21-23]}$. Furthermore, Zhong et al ${ }^{[24]}$ found that the introduction of the shortwave infrared band (MODIS band 6) could perfectly distinguish between soybean and maize which had similar phenological phases.

Previous studies on the extraction of soybean and maize -growing areas mostly focused on the countries or regions with concentrated and continuous cropping and a high degree of industrialization, e.g., the United States, Brazil, and Northeast China ${ }^{[25-27]}$. It is obvious that some difficulties are still encountered in studies on soybean and maize mapping at the remote-sensing level, especially in areas with great challenges e.g., the Huang-Huai-Hai area, which is one of the main production areas of soybean and maize in China but has received little attention to date. First and foremost, the high frequency of cloud cover arising from the changeable weather during the key growth stages of soybean and maize results in a significant reduction in available satellite images. Second, the complexity of planting structure here brought by smallholder farming poses a huge challenge to the remote-sensing identification of the two crops. Moreover, the phonological similarity between soybean and maize also increases the difficulty of this task.

Sentinel-2 data with relatively high resolution (up to $10 \mathrm{~m}$ ) is expected to be more appropriate for crop mapping in areas with complex summer-crop planting structure compared with the data source with low resolution, e.g., MODIS (500 m and $250 \mathrm{~m})^{[28]}$. The working bands of the Sentinel-2 sensor with a higher temporal resolution (5-day revisit period), covering from visible to shortwave infrared spectral scope offer a richer band setting than the Landsat series of satellites. Thus, it is extensively used to monitor global vegetation in view of the aforementioned advantages $^{[29,30]}$. Anhui Province is situated in the main soybean and maize production areas of Huang-Huai-Hai area. The study area with substantial maize and soybean cultivation in Anhui Province was selected in the present study to explore appropriate methods of soybean and maize mapping through remote-sensing technology.

Accordingly, the specific objectives of this study were to: (1) determine the optimum time phase for soybean and maize identification based on multi-temporal Sentinel-2 data; (2) select the optimum classifier to extract soybean and maize-planting areas; (3) screen out the optimum feature-subset to identify the fields of soybean and maize.

\section{Materials}

\subsection{Study area}

The acreage of soybean cultivation in Anhui Province has exceeded $600 \mathrm{khm}^{2}$ and is second only to Heilongjiang Province and Inner Mongolia Autonomous Region, ranking third in China; the maize-planting area in the province reaches more than $1130 \mathrm{khm}^{2}$, ranking around the tenth in the country (data from China Rural Statistical Yearbook in 2019). Bozhou, located in northern Anhui Province, is the traditional main producing area of maize and high-protein soybean in Huang-Huai-Hai area. Its soybean-cultivated area always maintains the first place among all municipal administrative units in the province; the acreage of maize in the city ranks the third in the province (data from 2019 Anhui Statistical Yearbook). Guoyang as a county under the jurisdiction of Bozhou spans the spatial scope between $33^{\circ} 27^{\prime} \mathrm{N}-33^{\circ} 47{ }^{\prime} \mathrm{N}$ and $115^{\circ} 53^{\prime} \mathrm{E}-116^{\circ} 33^{\prime} \mathrm{E}$. Over the years, it has the largest soybean planting scale (more than $72 \mathrm{khm}^{2} /$ year) in the province. Soybean and maize-cropped areas account for about $54 \%$ and $37 \%$ of the total area of summer food crops in the county, respectively (data from 2019 Bozhou Statistical Yearbook). The terrain here is dominated by plains with average elevation of 26.5-33.5 m. It has warm temperate semi-humid monsoon climate; the annual average temperature is about $15.1^{\circ} \mathrm{C}$ and the annual precipitation is about $851.6 \mathrm{~mm}$. Given the superior natural conditions, it is suitable for the growth of various summer crops, e.g., soybean, maize, sorghum, sweet potatoes, and various Chinese medicinal materials in the same season. With Guohe river as the boundary, the northern part of the county is dominated by soybean, while maize is overwhelming in the southern area. Two towns, Longshan and Qingtuan, as the typical soybean and maize-producing areas were selected as the study area in the present research (Figure 1). The farmland landscape is fragmented due to small-holder farming and mixed-planting of different crops, with small patch size of cropland. Generally, the 
phenological stages of soybean and maize (http://data.cma.cn/) are similar to each other (Figure 2).

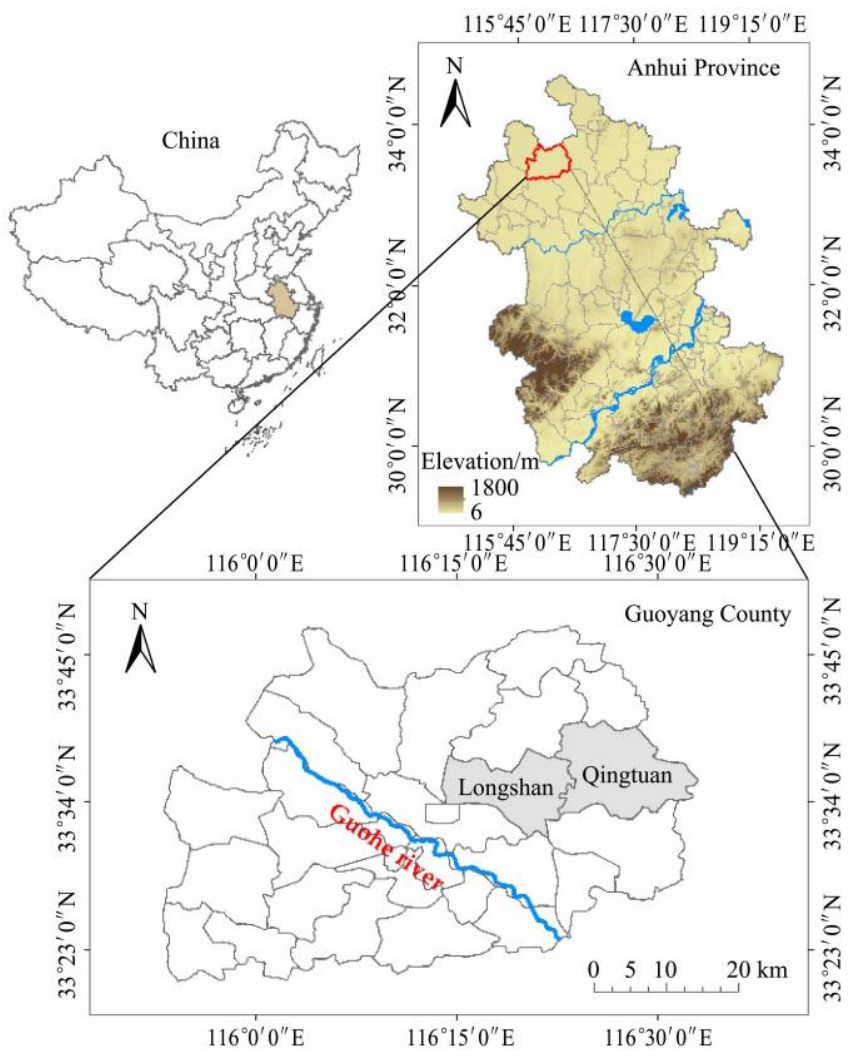

Figure 1 Map of the study area

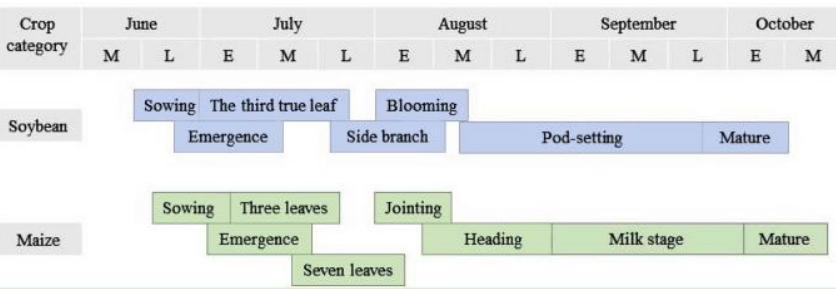

Note: E, M, and L represent the early, middle, and last 10-day of a month, respectively.

Figure 2 Phenological stages of soybean and maize in Bozhou City, Anhui Province

\subsection{Sentinel-2 data}

The Copernicus Sentinel-2 mission comprises a constellation of two polar-orbiting satellites: $2 \mathrm{~A}$ and $2 \mathrm{~B}$, which were launched on June 23, 2015, and March 7, 2017, respectively. Sentinel-2 is a high-resolution multispectral operational imaging mission for global land observation, each one carries a multispectral instrument (MSI) with a wide swath width $(290 \mathrm{~km})$ and high revisit capability ( $10 \mathrm{~d}$ at the equator with one satellite, and $5 \mathrm{~d}$ with two satellites under cloud-free conditions) ${ }^{[31]}$. A total of thirteen working bands are designed, covering the spectral range from visible to short-wave infrared, as well as three levels of spatial resolution $(10 \mathrm{~m}, 20 \mathrm{~m}$ and $60 \mathrm{~m}$ ) dedicated to identifying spatial details consistent with $1 \mathrm{hm}^{2}$ minimum mapping unit (Table 1$)^{[32]}$. Moreover, among all multispectral sensors, Sentinel-2 MSI is the only one providing three spectral bands in the red-edge spectral scope, which is very effective for vegetation monitoring ${ }^{[33]}$.

In this study, three Sentinel-2 images in good quality were available throughout the entire soybean and maize growing season in 2019 owing to the limitation of clear observation. These images were provided by the ESA Copernicus Open Access Hub (https://scihub.copernicus.eu/) (Table 2).
Table 1 Specifications of the multispectral instrument (MSI) mounted on Sentinel-2 satellite constellation

\begin{tabular}{ccccc}
\hline $\begin{array}{c}\text { Band } \\
\text { number }\end{array}$ & Band name & $\begin{array}{c}\text { Central } \\
\text { wavelength/nm }\end{array}$ & $\begin{array}{c}\text { Band } \\
\text { width/nm }\end{array}$ & $\begin{array}{c}\text { Spatial } \\
\text { resolution/m }\end{array}$ \\
\hline 1 & Coastal & 443 & 20 & 60 \\
2 & Blue & 490 & 65 & 10 \\
3 & Green & 560 & 35 & 10 \\
4 & Red & 665 & 30 & 10 \\
5 & Vegetation Red Edge & 705 & 15 & 20 \\
6 & Vegetation Red Edge & 740 & 15 & 20 \\
7 & Vegetation Red Edge & 783 & 20 & 20 \\
8 & NIR & 842 & 115 & 10 \\
$8 \mathrm{~A}$ & Narrow-NIR & 865 & 20 & 20 \\
9 & Water Vapor & 945 & 20 & 60 \\
10 & SWIR-Cirrus & 1375 & 30 & 60 \\
11 & SWIR & 1610 & 90 & 20 \\
12 & SWIR & 2190 & 180 & 20 \\
\hline
\end{tabular}

Table 2 Sentinel-2 data employed in the study

\begin{tabular}{lccc}
\hline Acquisition date & $\begin{array}{c}\text { Number of } \\
\text { scenes }\end{array}$ & $\begin{array}{c}\text { Soybean growth } \\
\text { stage }\end{array}$ & $\begin{array}{c}\text { Maize growth } \\
\text { stage }\end{array}$ \\
\hline August 18, 2019 & 1 & Early pod-setting & Heading \\
August 28, 2019 & 1 & Middle pod-setting & Heading \\
September 7, 2019 & 1 & Late pod-setting & Heading \\
\hline
\end{tabular}

\subsection{Field survey and unmanned aerial vehicle imaging}

Six ground samples were set evenly in the study area (each was $1 \mathrm{~km} \times 1 \mathrm{~km}$ in size), considering to minimize the proportion of the built-up area (Figure 3). Images of the six ground samples were captured using DJI-Phantom4 Pro during September 7-9, 2019. A high-resolution digital camera with a field of view of $84^{\circ}$ and a 1-inch 20-megapixel CMOS sensor was mounted onto the unmanned aerial vehicle (UAV) to acquire RGB images in JPEG format. All flight missions were implemented at $200 \mathrm{~m}$ altitudes with a forward overlap of $80 \%$ and a side overlap of $80 \%$ under favorable weather conditions in these 3 days; the spatial resolution of the image was about $6 \mathrm{~cm}$. To obtain high spatial-positioning accuracy of UAV images, four image control points originated from clearly discernible ground features were deployed in each ground sample, and the geographic coordinates (longitude and latitude) of each control point were measured by Real-Time Kinematic (RTK) (CHCNAV i70, China).

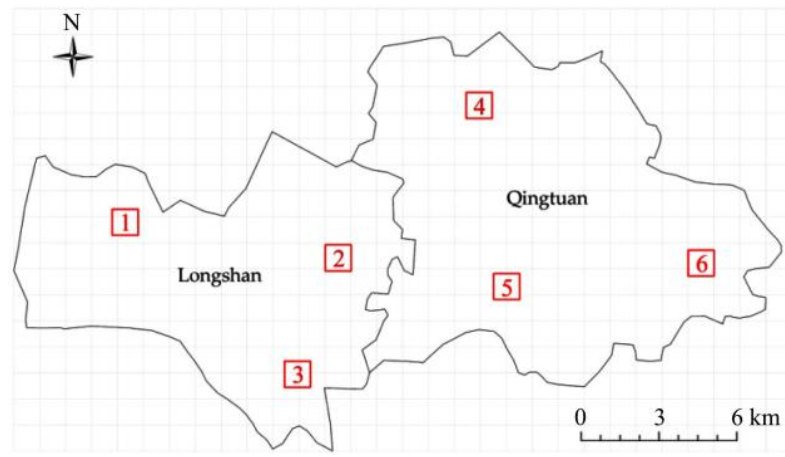

Figure 3 Spatial distribution of the six ground samples with labels

Field survey was conducted simultaneously when the UAV images were acquired. 212 ground survey plots covering the main land-cover types in the study area were selected. A hand-held GPS (Trimble Geo7X, USA) was used to obtain the geographic coordinates of each survey plot, and the corresponding land-cover types were also recorded in detail. The numbers of survey plots 
for soybean, maize, sorghum, bare soil, and other vegetation were $91,79,13,5$, and 24 , respectively.

All other non-remote sensing data adopted were mainly town-level administrative boundary (in vector form) of Guoyang and statistics on the sown area of major crop types.

\section{Methods}

\subsection{Data preprocessing}

Only the bands with $10 \mathrm{~m}$ and $20 \mathrm{~m}$ resolution were adopted in this research. First, the atmospheric correction was performed using Sen2Cor processor (version 2.8, http://step.esa.int/main/ third-party-plugins-2/sen2cor/) to convert top-of-atmosphere (TOC) Level $1 \mathrm{C}$ data to bottom-of-atmosphere (BOC) reflectance. The output was resampled to $10-\mathrm{m}$ spatial resolution and then exported to ENVI format under the environment of the Sentinel Application Platform (SNAP) (version 7.0.0, http://step.esa.int/main/download/), the bilinear interpolation method was applied. Finally, the data were subset with Longshan and Qingtuan administrative boundaries by using ENVI 5.3 to obtain the image of the study area.

As for the UAV images, a quality check was carried out first to eliminate the scenes with poor imaging quality. Subsequently, the qualified UAV images were imported into ContextCapture Center (version 4.4.9), and image matching, aerotriangulation and texture mapping would be automatically completed to generate dense point clouds, then a triangulated irregular network (TIN) model was constructed from this. The digital orthophoto map (DOM) was produced later based on TIN and the control points. Finally, we employed Global Mapper (version 19.0) to mosaic the DOM images to achieve the complete coverage of each ground sample.

\subsection{Selection of the optimum time phase for soybean and} maize identification

Sentinel-2 images of three-time phases were selected in this study. Remote-sensing identification of soybean and maize required high separability between these two crops as well as other cover types, which depended largely on the acquisition time of images. Previous studies indicated that the Jeffries-Matusita (JM) distance based on the conditional probability theory is more suitable for describing inter-class differences than other indicators, and it can effectively evaluate the separability between training samples of various cover types ${ }^{[34]}$. In this study, the JM distance was employed as a quantitative evaluation indicator of the separability among different land-cover types in these three-time phases, so as to determine the optimum one for soybean and maize mapping. According to the field survey, sparsely distributed vegetation e.g., weed, sweet potato, peanut, vegetables, watermelon, and sesame were collectively termed as "others". Thus, eight main land-cover types (soybean, maize, sorghum, artificial objects, trees, water body, bare soil, and others) with more than 50 sample sets of each type were selected through the ground survey campaign and visual interpretation with the support of Google Earth.

The JM distance between a pair of type-specific probability functions is computed as follows ${ }^{[35]}$ :

$$
J M\left(c_{j}, c_{k}\right)=\int_{x}\left[\sqrt{P\left(x \mid c_{j}\right)}-\sqrt{P\left(x \mid c_{k}\right)}\right]^{2} d x
$$

where, $x$ is the data value of different bands; $c_{j}$ and $c_{k}$ are the two different crops or other land-cover types under consideration.

Under the normality assumptions, Equation (1) can be defined as Equation (2):

$$
J M=2\left(1-e^{-B}\right)
$$

$$
B=\frac{1}{8}\left(\mu_{j}-\mu_{k}\right)^{T}\left(\frac{\sum j+\sum k}{2}\right)^{-1}\left(\mu_{j}-\mu_{k}\right)+\frac{1}{2} \ln \left(\frac{\left|\frac{\sum j+\sum k}{2}\right|}{\sqrt{\left|\sum j\right|\left|\sum k\right|}}\right) \text { (3) }
$$

where, $\mu_{j}$ and $\mu_{k}$ represent the mean values of the spectral reflectance of two specific cover types; $T$ is the transpose function, and $\sum j, \sum k$ are the unbiased estimates for the covariance matrices of $j$ and $k$, respectively ${ }^{[36]}$.

The JM distance, which ranges from 0 to 2 , describes the degree of separability between the two specific cover types ${ }^{[37]}$. The greater JM distance is, the better separability between the two classes is.

\subsection{Screening out the optimum classifier for soybean and maize extraction}

Machine-learning algorithms can achieve high-accuracy ground object extraction based on single-phase data, which is also a convenient, high-efficiency, and extensively used method of crop mapping. The selection of optimum classifier is very important for obtaining reliable extraction results. Accordingly, three commonly used machine-learning methods were adopted in this study as candidate classifiers and described as follows.

\subsubsection{Support Vector Machine}

Support Vector Machine (SVM) proposed by Cortes and Vapnik in 1995 is an effective and extensively used method of ground-objects classification ${ }^{[38]}$. It has attracted considerable attention in the field of crop mapping by remote sensing ${ }^{[39]}$. SVM is designed to establish a hyperplane and maximize the distance between the samples on both sides of the hyperplane to separate different classes. This technique is a suitable machine-learning method for a small set of samples with a strong theoretical basis; it can automatically learn the classification knowledge of samples in the case of small sample size and obtain good results ${ }^{[38,40]}$.

The SVM classifier provided by ENVI 5.3 was used to map soybean and maize. In light of the non-linear relationship between the classification results and the input feature variables, classification was implemented through the radial basis function (RBF) kernel, which had certain advantages in crop identification ${ }^{[41]}$. Four parameters needed to be set: the value of classification probability threshold was set to zero to ensure that all pixels participated in classification and each one was defined as a specified cover type; the value of the pyramid parameter was also set to zero for the purpose of processing the image at its original resolution; the kernel width (gamma) was set to 0.1 and the penalty parameter kept the default value.

\subsubsection{Back-Propagation Neural Network}

Back-Propagation Neural Network (BPNN) developed by Rumelhart in 1986 is a multi-layer feed-forward neural network trained according to the error back-propagation algorithm ${ }^{[42]}$. BPNN with strong nonlinear, high self-learning and adaptive ability is one of the most popular techniques in artificial neural networks and can effectively extract crop-planting information in the agricultural field ${ }^{[43]}$. The learning rule for the entire network is to make the error reach the expected minimum value by constantly adjusting the weights and thresholds between neurons through the gradient-descent method. In this work, soybean and maize were mapped with the aid of the Neural Net Classification module of ENVI 5.3 under default parameters, using the same set of training samples as SVM method.

\subsubsection{Random Forest}

Random Forest (RF) is a machine-learning algorithm that has 
been increasingly reported in remote-sensing crop mapping owing to its high efficiency, strong adaptability and anti-noise ability ${ }^{[44,45]}$. It works well with large and high-dimensional datasets by using a set of classification and regression trees ${ }^{[46]}$. Each tree is trained with two-thirds of data randomly selected from the original dataset, and the remaining one-third called out-of-bag (OOB) data is not actually involved in growing the tree ${ }^{[47]}$. The OOB error produced by the OOB data is an unbiased estimate of the RF generalization error to assess the RF model's performance.

For RF method, two key user-defined parameters are required to build the model. One of the parameters is the number of decision trees (ntree), and the other is the number of features (mtry) used in each split node. Several studies have revealed that RF can obtain satisfactory results with default parameters ${ }^{[48,49]}$. The mtry was kept the default value that was the square root of the number of all features. We found that under the default setting of mtry, ntree had little effect on the classification accuracy when the number of ntree was more than 100 . Therefore, ntree was set to 100 .

\subsubsection{Selection of the optimum classifier}

The above three machine-learning algorithms have their unique advantages, and determining the optimum classifier for soybean and maize extraction in the study area is particularly crucial. Accordingly, these three methods were applied to the image singled out in the previous step to compare their performance in crop identification.

In general, the accuracy of spatial distribution can most suitably be evaluated by the confusion matrix ${ }^{[50]}$. Overall accuracy, user accuracy, producer accuracy, and Kappa coefficient were generated from the confusion matrix to assess the performance of the three classifiers. Kappa was calculated as follows ${ }^{[5,51]}$.

$$
\text { Kарpa }=\frac{N \sum_{i=1}^{m} x i i-\sum_{i=1}^{m} x_{i+} \times x_{+i}}{N^{2}-\sum_{i=1}^{m} x_{i+} \times x_{+i}}
$$

where, $N$ denotes the number of pixels; $m$ is the number of categories; $x i i$ is the number of pixels on the diagonal of the confusion matrix; $x_{i+}$ and $x_{+i}$ are the sum of the number of pixels in row and column $i$.

254 ground truth plots (covering eight main land-cover types) from field survey and visual interpretation with the aid of Google Earth were used to generate the confusion matrix. Extraction results of different classification methods were evaluated with Kappa coefficients, and the optimum classifier was screened out accordingly.

\subsection{Screening out the optimum feature-subset for soybean} and maize identification

\subsubsection{Description of candidate features}

Twenty features were selected and applied to subsequent analyses targeted at screening out the optimum feature-combination. The well-behaved features were expected to be more sensitive to soybean and maize and contribute more to the mapping of both crops. The candidate features included reflectance of the ten spectral bands with a spatial resolution at $10 \mathrm{~m}$ and $20 \mathrm{~m}$, which were referred to as B2, B3, B4, B5, B6, B7, B8, B8A, B11, and $\mathrm{B} 12$ (Table 1), and the ten additional features (Table 3) generated from these ten bands. Previous studies showed that red-edge bands were favorable for soybean and maize extraction ${ }^{[52]}$. It was worth mentioning that for the red-edge NDVI, only two forms calculated from two red-edge bands (B5 and B6) were adopted because we found that the NDVI generated based on B7 (783 nm at central wavelength) was of poor quality.

Table 3 Description of the ten additional features used in this study

\begin{tabular}{|c|c|c|}
\hline Name & Expression & Reference \\
\hline $\begin{array}{l}\text { Enhanced Vegetation Index } \\
\text { (EVI) }\end{array}$ & $2.5 \times \frac{B 8-B 4}{B 8+6 \times B 4-7.5 \times B 2+1}$ & $\begin{array}{l}\text { Huete et al., } \\
\qquad 2002^{[53]}\end{array}$ \\
\hline $\begin{array}{l}\text { Soil Adjusted Vegetation Index } \\
\text { (SAVI) }\end{array}$ & $1.5 \times \frac{B 8-B 4}{B 8+B 4+0.5}$ & $\begin{array}{l}\text { Huete, } \\
1988^{[54]}\end{array}$ \\
\hline $\begin{array}{l}\text { MERIS Terrestrial Chlorophyll } \\
\text { Index (MTCI) }\end{array}$ & $\frac{B 6-B 5}{B 5-B 4}$ & $\begin{array}{l}\text { Dash et al., } \\
2007^{[55]}\end{array}$ \\
\hline Red-Edge Position (REP) & $705+35 \times \frac{0.5 \times(B 4+B 7)-B 5}{B 6-B 5}$ & $\begin{array}{c}\text { Guyot et al., } \\
1988^{[56]}\end{array}$ \\
\hline $\begin{array}{l}\text { Normalized Difference } \\
\text { Vegetation Index (NDVI) }\end{array}$ & $\frac{B 8-B 4}{B 8+B 4}$ & $\begin{array}{c}\text { Rouse et al., } \\
1973^{[57]}\end{array}$ \\
\hline Red-edge NDVI (NDVIre1) & $\frac{B 8-B 5}{B 8+B 5}$ & $\begin{array}{l}\text { Gitelson, } \\
1997^{[58]}\end{array}$ \\
\hline Red-edge NDVI (NDVIre2) & $\frac{B 8-B 6}{B 8+B 6}$ & $\begin{array}{l}\text { Gitelson, } \\
1997^{[58]}\end{array}$ \\
\hline $\begin{array}{l}\text { Green Normalized Difference } \\
\text { Vegetation Index (GNDVI) }\end{array}$ & $\frac{B 8-B 3}{B 8+B 3}$ & $\begin{array}{l}\text { Gitelson, } \\
1997^{[58]}\end{array}$ \\
\hline $\begin{array}{l}\text { Normalized Difference Water } \\
\text { Index (NDWI) }\end{array}$ & $\frac{B 3-B 8}{B 3+B 8}$ & $\begin{array}{c}\text { McFeeters, } \\
1996^{[59]}\end{array}$ \\
\hline $\begin{array}{l}\text { Normalized Difference Building } \\
\text { Index (NDBI) }\end{array}$ & $\frac{B 11-B 8}{B 11+B 8}$ & Zha, $2003^{[60]}$ \\
\hline
\end{tabular}

3.4.2 Selection of the optimum feature-subset for soybean and maize identification

Not all features were effective enough for soybean and maize identification owing to the differences in sensitivity to specified ground objects. Hence, feature-subset optimization was necessary so as to screen out the features that contributed more to the mapping of these two crops ${ }^{[61]}$. The optimum feature-subset with a smaller data volume was expected to be more practical for maize and soybean identification. Numerous studies have revealed that the RF algorithm was attractive not only for classification but also for feature selection ${ }^{[48,62]}$. About 1000 samples covering all main land-cover types (soybean, maize, sorghum, artificial objects, trees, water body, bare soil, and others) were selected as input datasets to conduct the feature selection procedure. OOB error produced feature variable importance (FVI) and could thus be used to derive the importance of each candidate feature ${ }^{[46]}$. The importance score of feature $j$ is computed by Equation $(5)^{[63]}$.

$$
F V I_{j}=\frac{1}{N} \sum_{i=1}^{N}\left(O O B_{N i}^{j}-O O B_{O i}^{j}\right)
$$

where, $N$ denotes the number of decision trees, and $O O B_{N i}^{j}$ represents the $O O B$ error of decision tree $i$ for the feature $j$ without noise. If the $O O B$ error $\left(O O B_{O i}^{j}\right)$ changes obviously when noise is randomly added to feature $j$, it indicates that the feature $j$ has a great influence on the classification result, that is to say, the more important the feature is. The RF package in MATLAB 2018 was applied to evaluate the weights and ranks of different feature variables and thus select the optimum feature subset. In view of the uncertainty in the results of each operation arising from the inherent randomness of the RF method, we ran the algorithm fifty times and took the average as the output.

The optimum dimension of candidate features sorted by importance was investigated subsequently. In the present study, twenty features in descending order of importance were sequentially added to the optimum classifier for soybean and maize identification by using sequential forward selection (SFS ${ }^{[64]}$. In other words, one feature was added at a time. First, the feature 
with the highest score was taken as the basic input, and the classification accuracy was calculated using the optimum classifier. Then, the subsequent feature with a slightly lower score was added in turn, and a new dataset was constructed along with previous input to generate new accuracy. The program operated in this way until the resulting accuracy reached a stable level, or the accuracy no longer increased significantly as new features were added, indicating that a relatively higher accuracy could be achieved with fewer features and that the data volume and computational cost were significantly reduced.

3.4.3 Assessing the performance of the optimum subset of features

Three classification schemes were designed to conduct remote-sensing extraction of soybean and maize (Table 4) and further assess the performance of the optimum feature-subset. Scheme A mapped soybean and maize planting areas on the basis of the ten spectral bands of Sentinel-2; Scheme B employed all of the twenty features; Scheme $\mathrm{C}$ was conducted based on the result of feature selection.

Table 4 Description of different classification schemes

\begin{tabular}{cl}
\hline Scheme & \multicolumn{1}{c}{ Feature combination } \\
\hline A & $\begin{array}{l}\text { Reflectance of ten spectral bands (B2, B3, B4, B5, B6, B7, B8, } \\
\text { B8A, B11, and B12) }\end{array}$ \\
B & Total twenty features (ten spectral bands+ten additional features) \\
C & Optimum subset of the twenty features \\
\hline
\end{tabular}

UAV images covering the six ground samples (each was $1 \mathrm{~km} \times$ $1 \mathrm{~km}$ in size) (Figure 3) were applied to examine the accuracy of different classification schemes for soybean and maize extraction based on Sentinel-2 images. UAV images were processed to cover the same spatial scope as each ground sample. These images provided fine-enough surface texture, enabling easy identification and interpretation of ground objects. With the support of ArcGIS 10.4 software, we manually delineated the boundary of maize and soybean-planting areas in each ground sample and created vector layers as ground truth to generate confusion matrix, and then evaluate the accuracy of soybean and maize extraction results.

This study involved the following tasks: (1) data preparation; (2) determining the optimum time phase and classifier; (3) screening out the optimum feature-subset; and (4) assessing the performance of the optimum feature-subset based on three schemes. The overall technology roadmap is as follows (Figure 4).

\section{Results}

\subsection{Optimum time phase for soybean and maize mapping}

The separability (represented by JM distance) between soybean, maize, and other main land-cover types was calculated based on the available images of three time-phases (Table 5). Results showed that soybean, maize, and non-vegetation cover types, i.e., bare soil, water and artificial objects had always good separability. The values of JM distance derived from the images obtained on August 18 and 28 were all greater than 1.8, which were significantly higher than those of September 7. Moreover, the separability between soybean, maize and other land-cover types derived from the image on August 18 was better than the latter date, except for trees. In view of the fact that the cover types in the study area were primarily dominated by soybean and maize crops, these results demonstrated that August 18 (early pod-setting stage of soybean) was the optimum time phase for soybean and maize extraction. Therefore, the image on August 18 was selected to identify soybean and maize.

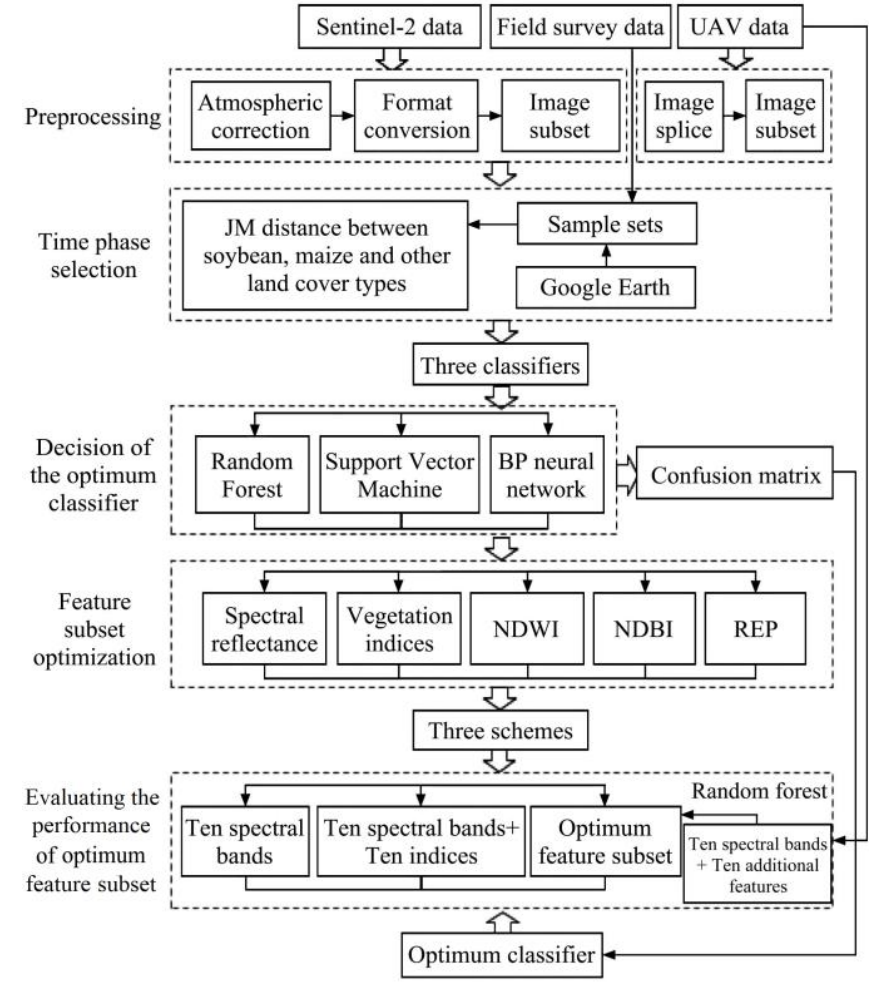

Figure 4 The overall technology roadmap of this study

Table 5 JM distance between soybean, maize, and other main land-cover types in different time phases

\begin{tabular}{lccc}
\hline \multicolumn{1}{c}{ Soybean } & August 18, 2019 & August 28, 2019 & September 7, 2019 \\
\hline Maize & 1.834 & 1.801 & 1.795 \\
Sorghum & 1.953 & 1.898 & 1.896 \\
Water & 1.998 & 1.998 & 1.998 \\
Artificial objects & 1.987 & 1.985 & 1.985 \\
Bare soil & 1.968 & 1.968 & 1.968 \\
Trees & 1.963 & 1.974 & 1.951 \\
Others & 1.892 & 1.836 & 1.554 \\
\hline \hline & August 18,2019 & August 28, 2019 & September 7, 2019 \\
\hline Soybean & 1.834 & 1.801 & 1.795 \\
Sorghum & 1.965 & 1.903 & 1.567 \\
Water & 1.999 & 1.999 & 1.998 \\
Artificial objects & 1.978 & 1.978 & 1.978 \\
Bare soil & 1.964 & 1.958 & 1.952 \\
Trees & 1.873 & 1.882 & 1.784 \\
Others & 1.971 & 1.954 & 1.853 \\
\hline
\end{tabular}

\subsection{Optimum classifier for soybean and maize mapping}

The mapping accuracy generated with the aid of 254 ground truth plots is given in Table 6. The overall accuracy of SVM, BPNN and RF classifiers were $84.65 \%, 85.04 \%$, and $87.00 \%$, and the corresponding Kappa coefficients were $0.80,0.80$, and 0.83 , respectively (Figure 5). Generally, RF showed better performance than the other two methods. In terms of the individual classification results of soybean and maize, SVM had higher producer accuracy for maize while user accuracy was relatively lower, whereas the situation for soybean was just the opposite. The results of BPNN were similar to those of SVM. RF outperformed the other two methods in the identification of soybean and also showed good behavior in maize extraction. In general, RF method with higher efficiency and accuracy was determined as the optimum classifier for soybean and maize extraction in this study. 
Table 6 Assessment of different classifiers in the extraction of main cover types

\begin{tabular}{|c|c|c|c|c|c|c|c|c|c|}
\hline Classifier & Accuracy $/ \%$ & Soybean & Maize & Sorghum & Trees & Artificial objects & Bare soil & Water body & Others \\
\hline \multirow{2}{*}{ SVM } & PA & 80.22 & 89.87 & 69.23 & 81.82 & 95.00 & 100.00 & 100.00 & 75.00 \\
\hline & UA & 85.88 & 79.78 & 56.25 & 90.00 & 100.00 & 100.00 & 87.50 & 100.00 \\
\hline \multirow{2}{*}{ BPNN } & PA & 89.01 & 82.28 & 92.31 & 45.45 & 80.00 & 100.00 & 100.00 & 87.50 \\
\hline & UA & 85.26 & 85.53 & 66.67 & 100.00 & 100.00 & 100.00 & 87.50 & 77.78 \\
\hline $\mathrm{RF}$ & PA & 90.11 & 88.61 & 92.31 & 54.55 & 85.00 & 100.00 & 100.00 & 75.00 \\
\hline
\end{tabular}

Note: PA: producer accuracy; UA: user accuracy.

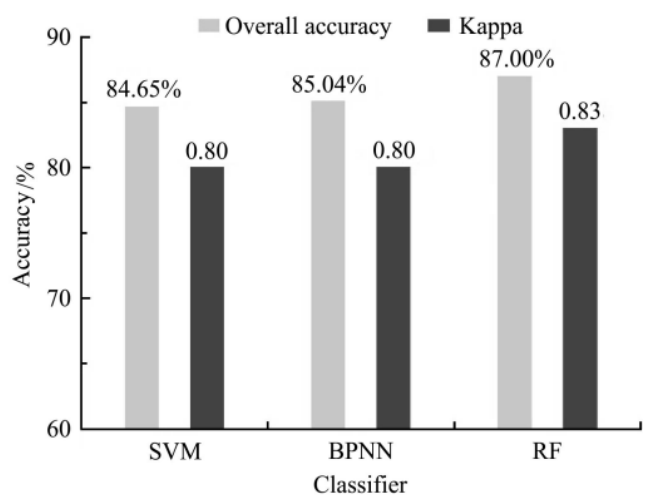

Figure 5 Comparison of the overall accuracy and Kappa coefficients corresponding to the three classifiers

\subsection{Optimum feature-subset for soybean and maize mapping}

Based on the Sentinel-2 image acquired on August 18th, the score of each candidate feature given by the RF algorithm was shown in Figure 6a in descending order. Results showed that B6 had the highest score (3.75) while the weight of NDWI was the lowest (0.19). B6 (red-edge band) contributed the most to the extraction of soybean and maize, whereas the feature of NDWI was

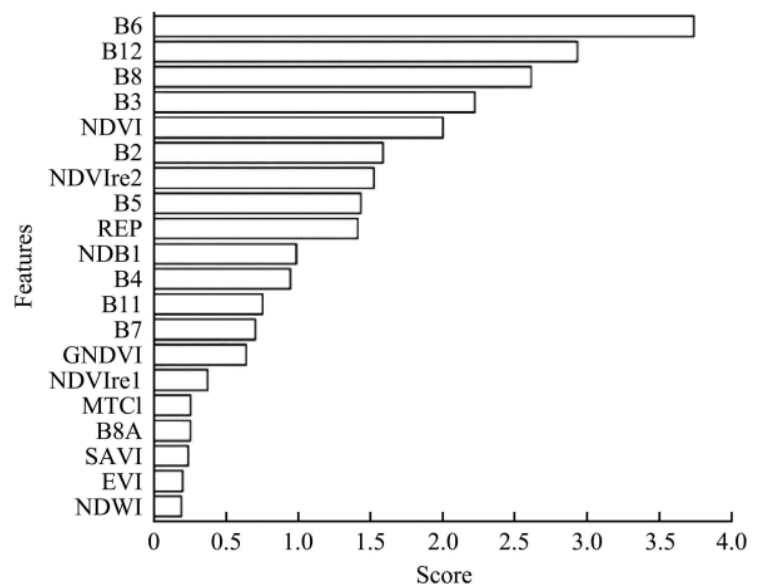

a. Ranking of the importance of candidate features in descending order the least important. B12 (short-wave infrared band) and B8 (near-infrared band) were also very important feature factors. B5 and REP related to red-edge characteristics, as well as the NDVIre2, calculated based on the red-edge band (B6) also ranked higher.

According to the determination method of the optimum dimension of feature-subset, B6 with the highest score was first added to the RF classifier, and the following feature with a relatively lower score was added in turn and formed new input, NDWI was the last one to be added. Then, the optimum number of input features was determined by the classification accuracy (Figure 6b). With more features added and served as input data, the accuracy initially kept increasing and reached the local maximum $(94.12 \%)$ when the number of features reached seven. However, with the number of features increased from seven to twenty, the accuracy did not obviously improve, and the overall accuracy fluctuated within a small range. Accordingly, we selected the top seven features (B6, B12, B8, B3, NDVI, B2, and NDVIre2) shown in Figure 6a as the optimum feature-subset for soybean and maize mapping. It meant that the performance of RF classifier was expected to be maintained by reducing $65 \%$ of the data volume and ensured a high-precision extraction result.

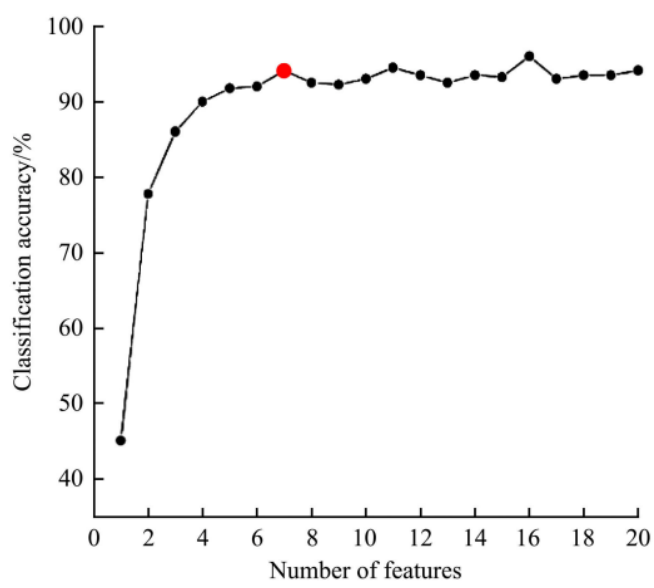

Note: Red dot indicates the number of optimum feature-subset

b. Relationship between the number of participated features and classification accuracy

Figure 6 Results of feature selection based on sequential forward selection (SFS) method

\subsection{Performance of different classification schemes}

The spatial distributions of soybean and maize in the study area are shown in Figure 7. They were obtained by RF classifier through the three classification schemes. The planting areas of soybean and maize derived from the UAV images were taken as the ground truth to assess the accuracy of these classification schemes. The classification results of the six ground samples (Figure 8) exhibited obvious differences between the results of scheme A and those of the other two schemes. The results of scheme $\mathrm{B}$ and $\mathrm{C}$ were more consistent with ground truth derived from UAV images, indicating that these two schemes could achieve higher accuracy of maize and soybean mapping.
The resultant accuracy corresponding to the three classification schemes of each ground sample is listed in Table 7. Compared with scheme $\mathrm{A}$, the extraction effect of schemes $\mathrm{B}$ and $\mathrm{C}$ was significantly improved in all ground samples. The Kappa coefficients of samples 1,3 , and 6 derived from scheme B and C reached up to more than 0.80 ; and those of samples 2,4 and 5 also exceeded 0.70 . In general, scheme B performed slightly better than scheme C. Therefore, the application of the optimum feature-subset in soybean and maize mapping could achieve a high level of accuracy with great advantages in data volume and runtime.

The ground truth of soybean and maize from UAV images 
(Figure 8) can explain the difference in the extraction effect among different ground samples. The farmland in samples 2, 4, and 5 had a higher degree of fragmentation, and many maize fields were more scattered and smaller in patch size, which greatly increased the difficulty of remote-sensing identification. The distributions of soybean and maize in samples 1, 3, and 6 were relatively more concentrated, enabling a better effect than the other three ground samples.

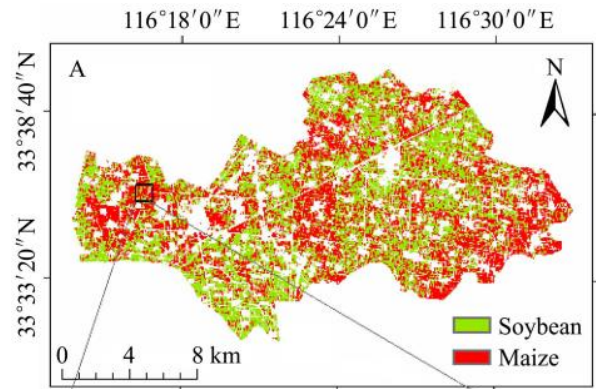

$116^{\circ} 18^{\prime} 0^{\prime \prime} \mathrm{E} \quad 116^{\circ} 24^{\prime} 0^{\prime \prime} \mathrm{E} \quad 116^{\circ} 30^{\prime} 0^{\prime \prime} \mathrm{E}$
$116^{\circ} 16^{\prime} 25^{\prime \prime} \mathrm{E}$
$116^{\circ} 16^{\prime} 56^{\prime \prime} \mathrm{E}$

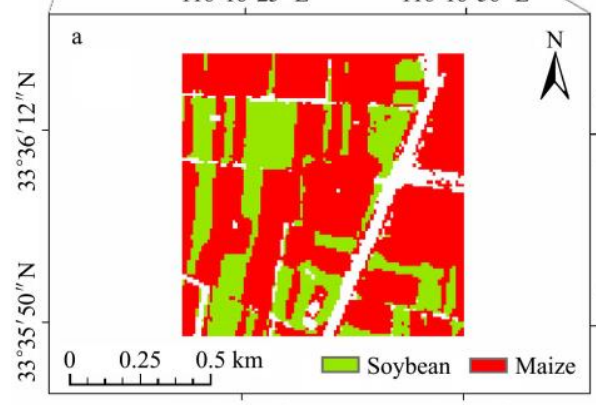

$116^{\circ} 16^{\prime} 25^{\prime \prime} \mathrm{E}$

$116^{\circ} 16^{\prime} 56^{\prime \prime} \mathrm{E}$

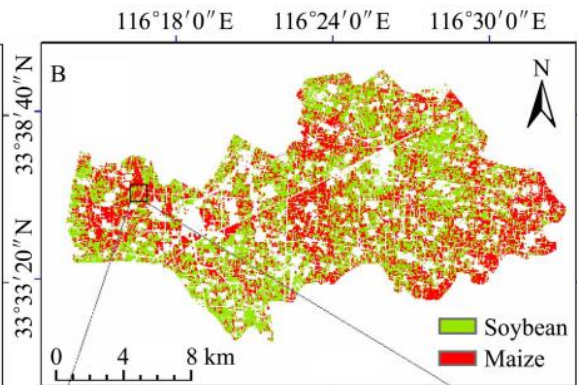
$116^{\circ} 18^{\prime} 0^{\prime \prime} \mathrm{E} \quad 116^{\circ} 24^{\prime} 0^{\prime \prime} \mathrm{E} \quad 116^{\circ} 30^{\prime} 0^{\prime \prime} \mathrm{E}$
$116^{\circ} 16^{\prime} 25^{\prime \prime} \mathrm{E}$
$116^{\circ} 16^{\prime} 56^{\prime \prime} \mathrm{E}$
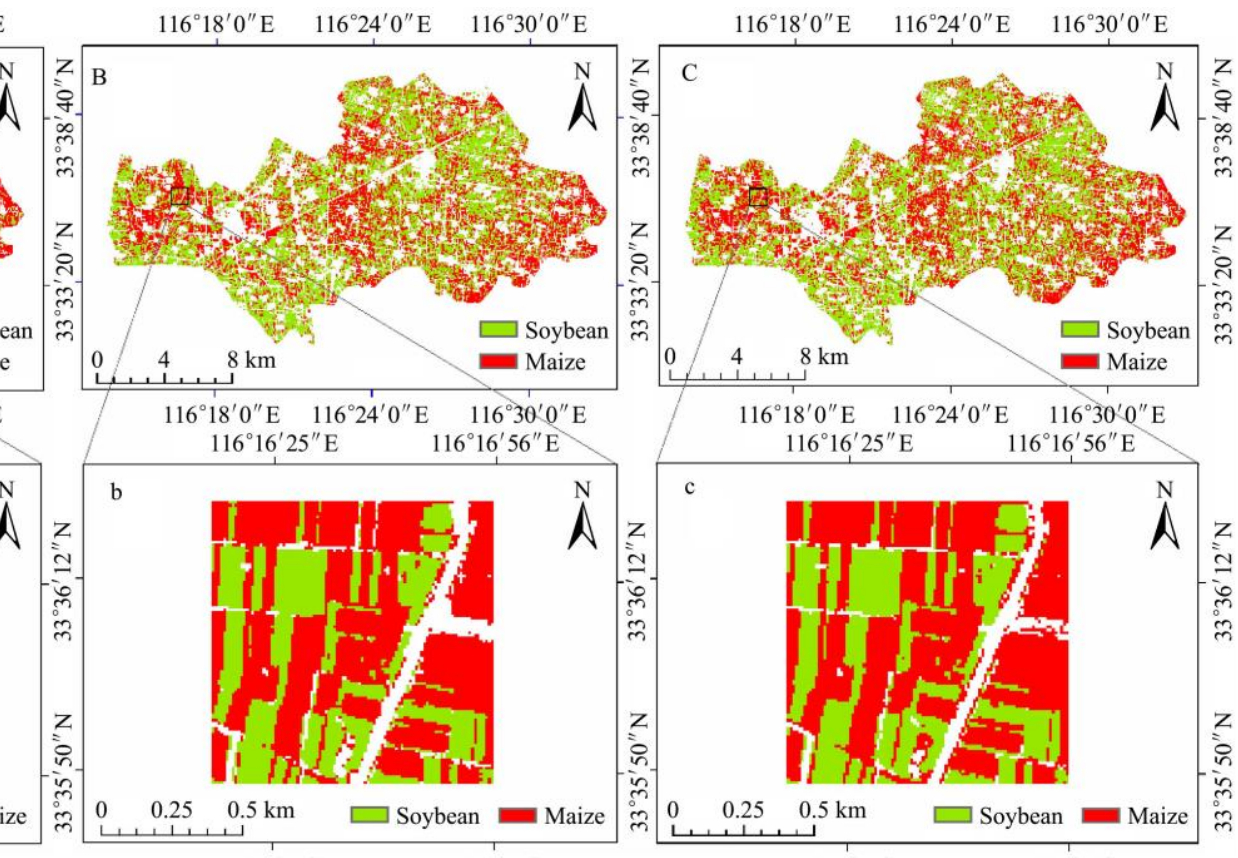

$116^{\circ} 16^{\prime} 25^{\prime \prime} \mathrm{E}$

$116^{\circ} 16^{\prime} 56^{\prime \prime} \mathrm{E}$

$116^{\circ} 16^{\prime} 25^{\prime \prime} \mathrm{E}$

$116^{\circ} 16^{\prime} 56^{\prime \prime} \mathrm{E}$

Figure 7 Crop maps generated from schemes A, B, and C (a, b, and c are local zooms providing detailed soybean and maize distributions corresponding to different schemes)

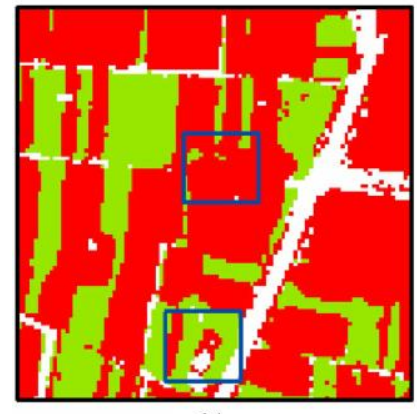

$1 \mathrm{~A}$

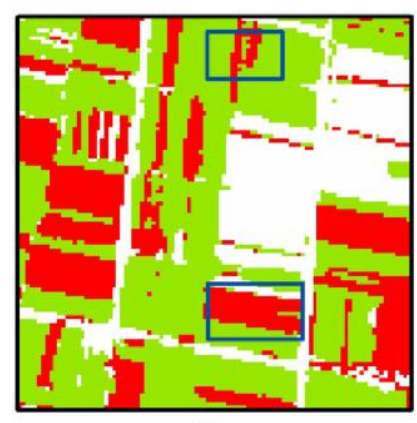

$2 \mathrm{~A}$

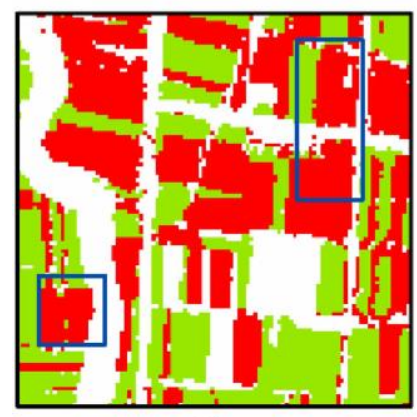

$3 \mathrm{~A}$
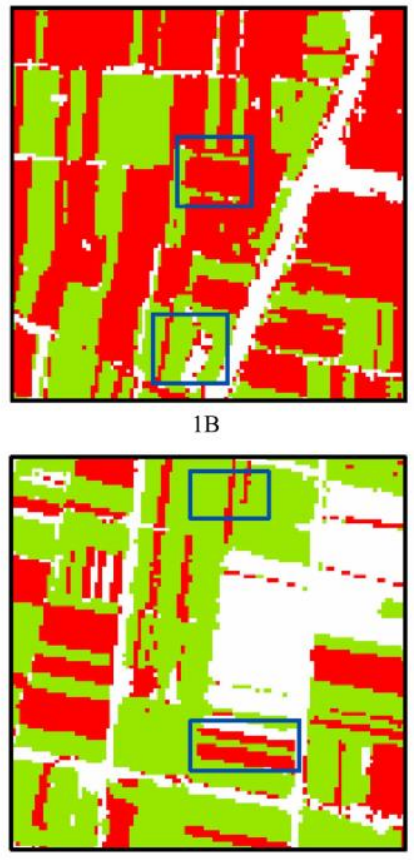

2B

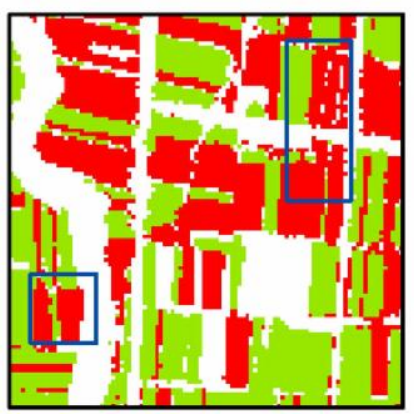

3B
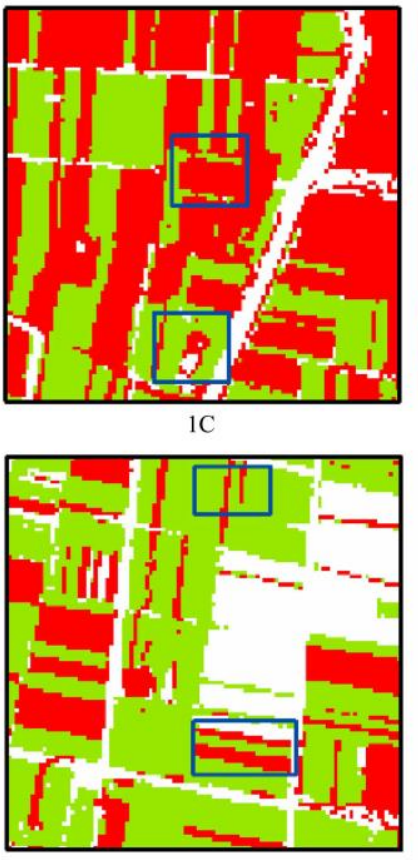

2C

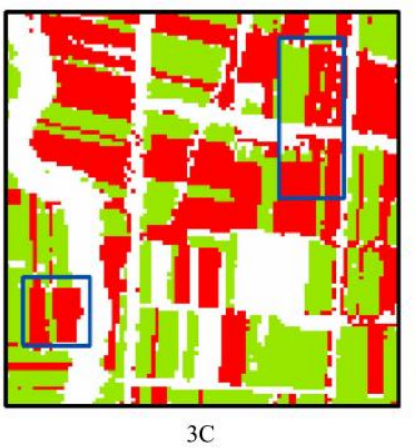

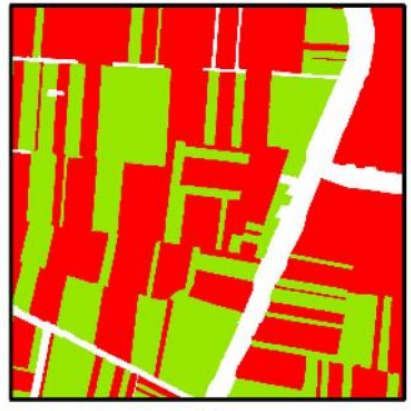

1D

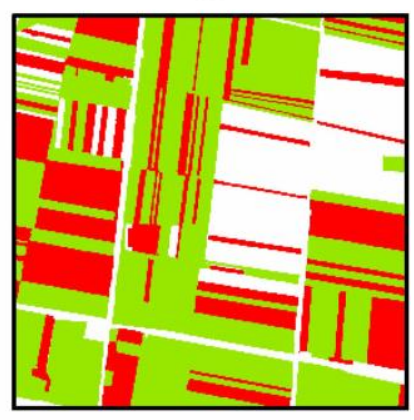

2D

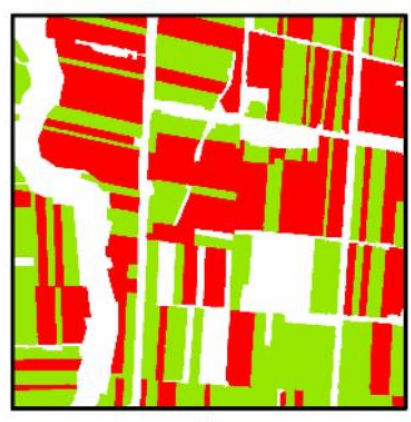

3D 


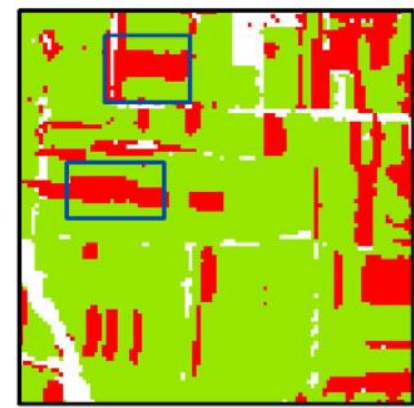

$4 \mathrm{~A}$
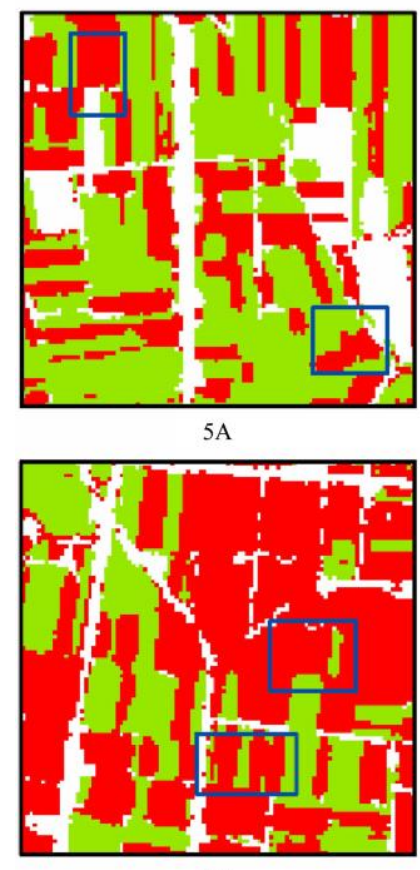

$6 \mathrm{~A}$

$0 \quad 0.25 \quad 0.5$

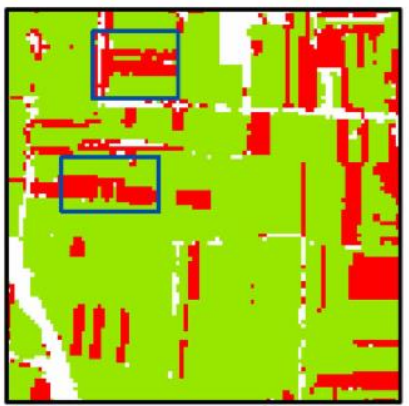

4B
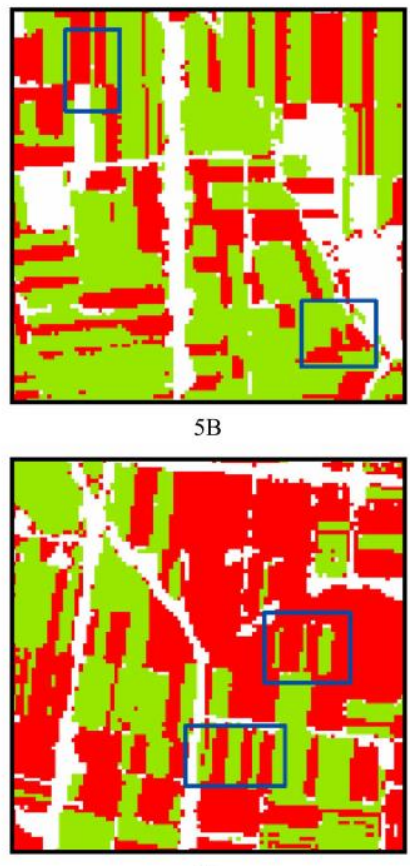

$6 \mathrm{~B}$

$1.0 \mathrm{~km}$

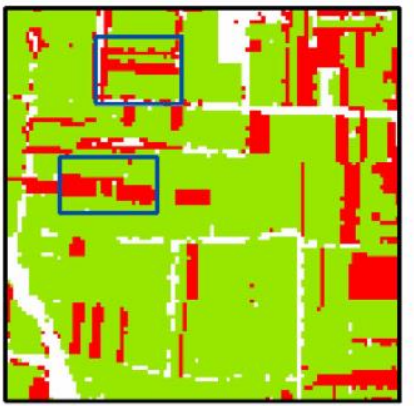

$4 \mathrm{C}$

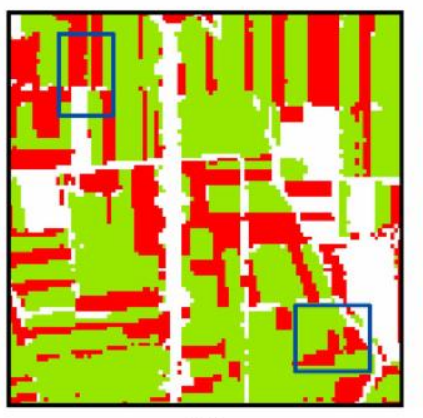

$5 \mathrm{C}$

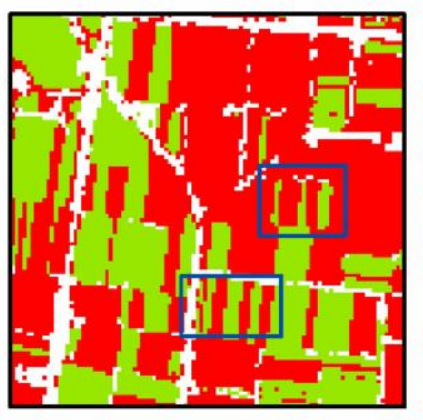

$6 \mathrm{C}$

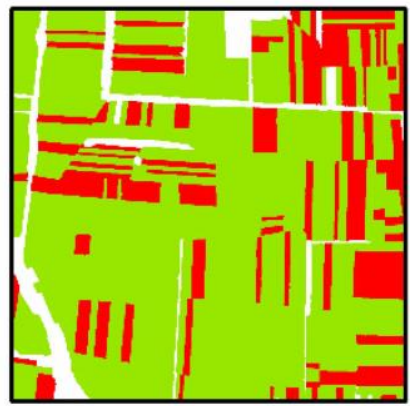

$4 \mathrm{D}$

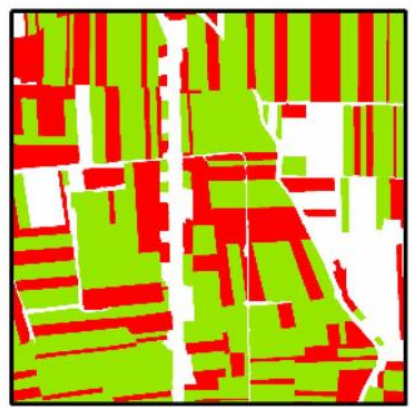

$5 \mathrm{D}$

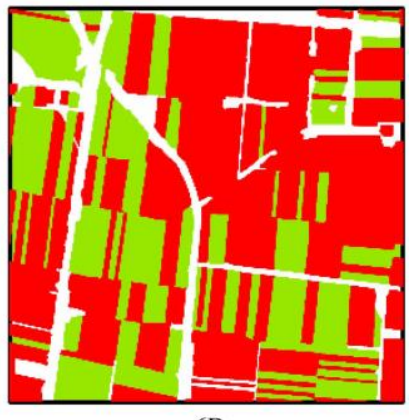

$6 \mathrm{D}$

$\square$ Soybean Maize

Figure 8 Extraction results of the six ground samples derived from different schemes: 1-6 represent the labels of the ground samples; A-C represent schemes A, B, and C; D represents the ground truth of soybean and maize planting areas generated from UAV images. The blue boxes highlight the regions with the most obvious differences in the results of the three schemes

Table 7 Accuracy evaluation results of schemes A, B and C

\begin{tabular}{|c|c|c|c|c|c|c|c|c|c|c|c|c|c|}
\hline \multirow{2}{*}{$\begin{array}{l}\text { Ground } \\
\text { sample }\end{array}$} & \multirow{2}{*}{ Crop } & \multicolumn{4}{|c|}{ A } & \multicolumn{4}{|c|}{ B } & \multicolumn{4}{|c|}{$\mathrm{C}$} \\
\hline & & $\mathrm{PA} / \%$ & $\mathrm{UA} / \%$ & $\mathrm{OA} / \%$ & Kappa & $\mathrm{PA} / \%$ & $\mathrm{UA} / \%$ & $\mathrm{OA} / \%$ & Kappa & $\mathrm{PA} / \%$ & $\mathrm{UA} / \%$ & $\mathrm{OA} / \%$ & Kappa \\
\hline \multirow{2}{*}{ Sample_1 } & Soybean & 71.81 & 92.49 & \multirow{2}{*}{86.64} & \multirow{2}{*}{0.71} & 87.68 & 89.84 & \multirow{2}{*}{91.31} & \multirow{2}{*}{0.82} & 88.84 & 88.25 & \multirow{2}{*}{91.01} & \multirow{2}{*}{0.81} \\
\hline & Maize & 96.23 & 84.07 & & & 93.64 & 92.21 & & & 92.41 & 92.80 & & \\
\hline \multirow{2}{*}{ Sample_2 } & Soybean & 89.01 & 88.39 & \multirow{2}{*}{85.27} & \multirow{2}{*}{0.68} & 94.44 & 87.11 & \multirow{2}{*}{87.27} & \multirow{2}{*}{0.71} & 95.57 & 85.91 & \multirow{2}{*}{86.99} & \multirow{2}{*}{0.70} \\
\hline & Maize & 78.37 & 79.39 & & & 73.84 & 87.64 & & & 71.23 & 89.76 & & \\
\hline \multirow{2}{*}{ Sample_3 } & Soybean & 85.97 & 88.89 & \multirow{2}{*}{88.17} & \multirow{2}{*}{0.76} & 93.45 & 88.38 & \multirow{2}{*}{91.01} & \multirow{2}{*}{0.82} & 93.83 & 86.42 & \multirow{2}{*}{90.14} & \multirow{2}{*}{0.80} \\
\hline & Maize & 90.18 & 87.57 & & & 88.78 & 93.69 & & & 86.84 & 94.03 & & \\
\hline \multirow{2}{*}{ Sample_4 } & Soybean & 94.29 & 91.55 & \multirow{2}{*}{88.96} & \multirow{2}{*}{0.68} & 97.13 & 91.67 & \multirow{2}{*}{90.99} & \multirow{2}{*}{0.73} & 97.68 & 90.60 & \multirow{2}{*}{90.49} & \multirow{2}{*}{0.71} \\
\hline & Maize & 71.49 & 79.26 & & & 70.51 & 88.01 & & & 67.26 & 89.98 & & \\
\hline \multirow{2}{*}{ Sample_5 } & Soybean & 82.54 & 82.63 & \multirow{2}{*}{86.66} & . 72 & 80.10 & 89.89 & 0000 & 7 & 78.44 & 91.52 & > & 75 \\
\hline & Maize & 89.22 & 89.17 & & 0.12 & 94.53 & 88.66 & 09.00 & 0.10 & 95.45 & 87.60 & 00.90 & 0.13 \\
\hline Somo 6 & Soybean & 78.93 & 89.50 & 0020 & 75 & 90.91 & 87.39 & 0122 & 092 & 92.83 & 85.77 & 0120 & Pe? \\
\hline 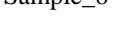 & Maize & 94.21 & 87.72 & 00.02 & $0.1 \mathrm{~J}$ & 91.61 & 94.03 & (31.J3 & 0.02 & 90.47 & 95.33 & 91.50 & 0.02 \\
\hline
\end{tabular}

Note: OA: overall accuracy; PA: producer accuracy; UA: user accuracy.

\section{Discussion}

The present study achieved high-quality mapping of soybean and maize in the typical producing areas in Anhui Province, China-based on Sentinel-2 data, and satisfactory results were produced. Results showed that Sentinel-2 data was appropriate for the identification of soybean and maize in areas with changeable weather, retail planting, complicated planting structure and highly fragmented farmland. Additionally, seven feature variables termed as the "optimum feature-subset" for soybean and 
maize extraction were screened out and five of them were spectral bands of Sentinel-2. Therefore, Sentinel-2 data has great advantages and prospects in soybean and maize mapping under complex planting conditions.

Five features, i.e., B6, B12, B8, B3, B2, which were the original bands of Sentinel-2 outperformed other spectral bands and remote-sensing indices. B6 as the variable related to red-edge characteristics ranked first among all the candidate features, indicating that red-edge related variables were very useful for soybean and maize mapping. B12 (short-wave infrared band) with its weight ranking second was indeed greatly beneficial to soybean and maize extraction, which was in line with the finding by Wang et al. ${ }^{[8]}$, who pointed out that the introduction of a short-wave infrared band could greatly improve the ability to identify and map soybean and maize when a single time-phase image was used. The near-infrared band (B8) was also a very important feature factor (ranking third), the differences between the typical spectra of different field vegetations in the near-infrared band were found to be obviously greater than those in the visible bands. Yin et al. ${ }^{[10]}$ demonstrated in their work that the near-infrared band was very effective for remote-sensing identification of soybean and maize, especially for conventional four-band sensors, which was confirmed in the present study.

The optimum feature-subset for the mapping of these two crops contained two VIs, i.e., NDVI and NDVIre2 in addition to the abovementioned spectral bands. NDVI is calculated from the red (B4) and near-infrared (B8) radiation reflected by ground objects $^{[57]}$, vegetation signals could be enhanced through normalization operation and some noise might be eliminated in some sense. NDVI is considered to be able to highlight certain crop information and amplify the differences between different crops. Thus, its performance in the identification of soybean and maize is probably better than some original working bands. Previous studies found that NDVI was very effective for distinguishing between different crops ${ }^{[6,13]}$. The results of this study also demonstrated that NDVI was useful for remote sensing extraction of soybean and maize. Moreover, the importance of NDVIre2 was also emphasized. NDVIre2 was the combination of red-edge (B6) and near-infrared (B8) bands, both of them have advantages in soybean and maize mapping. The normalization of the two bands contributed to the good performance of NDVIre2, which played an important role in crop identification.

RF method behaved better than SVM and BPNN in our study area. Generally, RF is insensitive to the dimension of the input dataset and has higher operational efficiency than SVM and BPNN. It can obtain higher classification accuracy under default parameter settings, and the parameter adjustment has less effect on the classification results compared with the other two methods ${ }^{[49]}$. Another advantage of RF method is that it can rank the importance of each input feature. When the input dataset has a high dimension, feature selection can be realized according to the importance to eliminate insignificant features and thus reduce the computational cost ${ }^{[9]}$

Regarding the optimization of candidate indicators and the determination of the optimum dimension of the features, only one method, i.e., RF was selected. Other methods of feature selection e.g., ReliefF, max-relevance and min-redundancy (mRMR) and correlation analysis will be considered in follow-up studies to further explore the optimum solution for the remote-sensing extraction of soybean and maize. In addition, only frequently used NDWI, NDBI, and several VIs were selected as the additional features in this study to conduct feature selection, these indicators may have their inherent limitations in the mapping of soybean and maize. Future research will take texture parameters, e.g., homogeneity, variance, dissimilarity, entropy, and correlation, etc. into consideration to investigate their performance in remote-sensing identification of soybean and maize.

Although the accuracy of crop identification using the optimum feature-subset (scheme C) was not as good as the combination of all candidate features (schemes B), the data volume of scheme $\mathrm{C}$ was reduced by $65 \%$ and the extraction accuracy was only slightly reduced. Therefore, the combination of optimum features is promising in practical application. In this work, ground truth maps were generated by visual interpretation and screen digitization method based on UAV images, which have centimeter-level resolution to verify the extraction results of soybean and maize-derived from Sentinel-2 images with a resolution of $10 \mathrm{~m}$. The main reason for manual digitization was that the acquisition time of the UAV images was late (September 7-9) in some sense for some personal reasons, and many soybean plots in the ground samples had entered the yellow ripening period, resulting in the coexistence of soybean fields in different phenological stages, which brought greater challenges to remote-sensing identification of this crop. The resolutions of the two data sources are not at the same level, the difference in spatial scale is obvious, and the high degree of farmland fragmentation in the study area also exacerbates the mismatch between these two results, which explains the relatively low Kappa coefficients to some extent. More space-borne high-resolution image data sources (e.g., SuperView-1 and GF-2) should be adopted to further examine the extraction effect in future work.

Generally, the method and approach of this study can provide a reference for the follow-up work and crop-identification related research. The conclusions are expected to be applicable to other producing areas of soybean and maize with similar growing conditions, crop types and planting structures in Huang-Huai-Hai region. However, the applicability of the findings of this study in the rest of China's main producing areas e.g., Southern China is still unclear and remains to be investigated. In addition, we are also examining the generalization of the conclusions in larger spatial scope and more growing seasons.

Some uncertainties and limitations also existed in the present study. Given the frequent cloud cover in the study area, some thin clouds on the image of September 7 might bring some uncertainties to the results obtained in this work. Moreover, the study area covering two towns was relatively small, and we only focused on one growing season of soybean and maize in 2019. Follow-up work will appropriately expand the scope of the study area and conduct remote-sensing identification of these two crops aimed at multiple growing seasons to test the robustness of the conclusions drawn in this study. Considering the highly complicated cropping patterns in the study area, a more systematic and comprehensive field survey is urgently needed in the future, and the removal of interference from non-agricultural land cover types may increase the accuracy as well.

\section{Conclusions}

An integrative study on the identification and mapping of soybean and maize in two towns in Guoyang County, Anhui Province was carried out using Sentinel-2 data. The performance of different time-phases, multiple classifiers, and multiple remote-sensing features in the identification of soybean and maize 
was investigated using machine-learning methods. Results revealed that the early pod-setting stage (August 18) of soybean was the optimum time phase for soybean and maize mapping and the RF algorithm was the most appropriate classifier. Moreover, the importance evaluation of twenty candidate features including spectral bands and remote sensing indices generated from them was performed. Results indicated that the top seven features (B6 (740 nm), B12 (2190 nm), B8 (842 nm), B3 (560 nm), NDVI, B2 $(490 \mathrm{~nm})$, and NDVIre2 (derived from B6 and B8)) were the most effective factors for maize and soybean identification, the role of the red edge-related variables was particularly highlighted. The superiority of the selected feature combination was confirmed in the subsequent results of ground-sample validation, with the ground truth stemming from UAV images. High-accuracy crop mapping was achieved (Kappa ranging from 0.70 to 0.82 ) by the optimum feature-subset, though slightly inferior to the input consisting of the total of twenty features, the data volume could be reduced greatly (by 65\%) compared with the latter. In addition, both schemes outperformed the results generated from ten working bands. Generally, the selected feature-combination had a broad application prospect in soybean and maize mapping.

The significance of this study lies in the approach of reliable remote sensing mapping of soybean and maize in areas with heterogeneous planting conditions in a relatively fast and low-cost way. This work could compensate for the lack of research on soybean and maize extraction in regions with complicated planting structures and fragmented farmland landscape. Relevant achievement of the present study can facilitate the development of precision agriculture in the field of crop mapping and may serve as a valuable reference for agricultural departments to make decisions.

\section{Acknowledgements}

This work was supported by the Key Project of Natural Science Research of Education Department of Anhui Province (Grant No. KJ2019A0120), the National Key Research and Development Program of China (2019YFE0115200) and the Open Research Fund of National Engineering Research Center for Agro-Ecological Big Data Analysis \& Application (Grant No. AE2018011). The authors appreciate the European Space Agency (ESA) which provides Sentinel-2 images for this research; the editor and anonymous reviewers for their valuable comments that helped us to improve this manuscript.

\section{[References]}

[1] Liu X, Rahman T, Song C, Su B Y, Yang F, Yong T, et al. Changes in light environment, morphology, growth and yield of soybean in maize-soybean intercropping systems. Field Crop. Res., 2017; 200: 38-46.

[2] Loy D, Lundy E. In: Sergio O (Ed.). Nutritional properties and feeding value of corn and its coproducts, corn, 3nd Ed. Eagan: AACC International Press, 2019; pp.633-659.

[3] Rebilas K, Klimek-Kopyra A, Bacior M, Zajac T. A model for the yield losses estimation in an early soybean (Glycine $\max (\mathrm{L}$.) Merr.) cultivar depending on the cutting height at harvest. Field Crop. Res., 2020; 254: 107846. doi: 10.1016/j.fcr.2020.107846.

[4] Wu F, Geng Y, Zhang Y Q, Ji C X, Chen Y F, Sun L, et al. Assessing sustainability of soybean supply in China: Evidence from provincial production and trade data. J. Clean Prod., 2020; 244: 1-14.

[5] Zhao L C, Shi Y, Liu B, Hovis C, Duan Y L, Shi Z C. Finer classification of crops by fusing UAV images and Sentinel-2A data. Remote Sensing, 2019; 11: 3012. doi: 10.3390/rs11243012.

[6] Huang J X, Hou Y Z, Su W, Liu J M, Zhu D H. Mapping corn and soybean cropped area with GF-1 WFV data. Transaction of the CSAE,
2017; 33: 164-170. (in Chinese)

[7] Weiss M, Jacob F, Duveiller G. Remote sensing for agricultural applications: A meta-review. Remote Sens. Environ., 2020; 236: 111402. doi: 10.1016/j.rse.2019.111402.

[8] Wang L M, Liu J, Yang L B, Yang F G, Fu C H. Impact of short infrared wave band on identification accuracy of corn and soybean area. Transaction of the CSAE, 2016; 32: 169-178. (in Chinese)

[9] Wang L M, Liu J, Yang L B, Yang F G, Fu C H. Application of random forest method in maize-soybean accurate identification. Acta. Agron. Sin. 2018; 44: 569-580.

[10] Yin L K, You N S, Zhang G L, Huang J X, Dong J W. Optimizing feature selection of individual crop types for improved crop mapping. Remote Sensing, 2020; 12: 1-20.

[11] Sidike P, Sagan V, Maimaitijiang M, Maimaitiyiming M, Shakoor N, Burken J, et al. dPEN: Deep Progressively Expanded Network for mapping heterogeneous agricultural landscape using WorldView-3 satellite imagery. Remote Sens. Environ., 2019; 221: 756-772.

[12] Jin Z N, Azzari G, You C, Di Tommaso S, Aston S, Burke M, et al. Smallholder maize area and yield mapping at national scales with Google Earth Engine. Remote Sens. Environ., 2019; 228: 115-128.

[13] de Souza C H, Mercante E, Johann J A, Lamparelli R A, Uribe-Opazo M A Mapping and discrimination of soya bean and corn crops using spectro-temporal profiles of vegetation indices. Int. J. Remote Sens., 2015; 36: 1809-1824.

[14] da Silva C A, Nanni M R, Teodoro P E, Silva G F. Vegetation indices for discrimination of soybean areas: A New Approach. Agron. J., 2017; 109: 1331-1343.

[15] Li X, Wang F, Xu D B, Liu Q W. Application research on the method for extracting soybean covered areas based on the pixel unmixing. Transaction of the CSAE, 2008; 24: 213-217.

[16] Sakamoto T, Wardlow B D, Gitelson A A, Verma S B, Suyker A E, Arkebauer T J. A two-step filtering approach for detecting maize and soybean phenology with time-series MODIS data. Remote Sens. Environ., 2010; 114: 2146-2159.

[17] Zhang J H, Feng L L, Yao F M. Improved maize cultivated area estimation over a large scale combining MODIS-EVI time series data and crop phenological information. ISPRS J. Photogramm. Remote Sens., 2014; 94: 102-113.

[18] Gu X H, Han L J, Wang J H, Huang W J, He X. Estimation of maize planting area based on wavelet fusion of multi-resolution images. Transaction of the CSAE, 2012; 28: 203-209. (in Chinese)

[19] Liu X X, Yu L, Zhong L H, Hao P Y, Wu B, Wang H S, et al Spatial-temporal patterns of features selected using random forests: A case study of corn and soybeans mapping in the US. Int. J. Remote Sens., 2019; 40: 269-283

[20] Chen Y L, Song X D, Wang S S, Huang J F, Mansaray L R. Impacts of spatial heterogeneity on crop area mapping in Canada using MODIS data. ISPR J. Photogramm. Remote Sens., 2016; 119: 451-461.

[21] Guo W, Zhao C, Gu X, Huang W, Ma Z, Wang H, et al. Remote sensing monitoring of maize planting area at town level. Transaction of the CSAE, 2011; 27: 69-74. (in Chinese)

[22] Hu Q, Sulla D, Xu B D, Yin H, Tang H J, Yang P, et al. A phenology-based spectral and temporal feature selection method for crop mapping from satellite time series. Int. J. Appl. Earth Obs. Geoinf., 2016; 80: 218-229.

[23] Zhong L H, Yu L, Li X C, Hu L N, Gong P. Rapid corn and soybean mapping in US Corn Belt and neighboring areas. Sci. Rep., 2016; 6: $1-14$.

[24] Zhong L H, Hu L N, Yu L, Gong P, Biging G S. Automated mapping of soybean and corn using phenology. ISPRS J. Photogramm. Remote Sens. 2016; 119: 151-164.

[25] Grzegozewski D M, Johann J A, Uribe-Opazo M A, Mercante E, Coutinho A C. Mapping soya bean and corn crops in the State of Parana, Brazil, using EVI images from the MODIS sensor. Int. J. Remote Sens., 2016; 37: $1257-1275$.

[26] Song X P, Potapov PV, Krylov A, King L, Di Bella C M, Hudson A, et al. National-scale soybean mapping and area estimation in the United States using medium resolution satellite imagery and field survey. Remote Sens. Environ., 2017; 190: 383-395.

[27] Gusso A, Guo W X, Rolim S B. Reflectance-based model for soybean mapping in United States at common land unit scale with Landsat 8. Eur. J. Remote Sens., 2019; 52: 522-531.

[28] Zhang H Y, Kang J Z, Xu X, Zhang L P. Accessing the temporal and 
spectral features in crop type mapping using multi-temporal Sentinel-2 imagery: A case study of Yi'an County, Heilongjiang province, China. Comput. Electron. Agric., 2020; 176: $105618 . \quad$ doi: 10.1016/j.compag.2020.105618.

[29] Macintyre, P.; van Niekerk, A.; Mucina, L. Efficacy of multi-season Sentinel-2 imagery for compositional vegetation classification. Int. J. Appl. Earth Obs. Geoinf. 2020, 85, 101980.

[30] Liu L, Xiao X M, Qin Y W, Wang J, Xu X L, Hu Y M, et al. Mapping cropping intensity in China using time series Landsat and Sentinel-2 images and Google Earth Engine. Remote Sens. Environ., 2020; 239: 111624. doi: 10.1016/j.rse.2019.111624.

[31] Drusch M, Del Bello U, Carlier S, Colin O, Fernandez V, Gascon F, et al. Sentinel-2: ESA's optical high-resolution mission for GMES operational services. Remote Sens. Environ., 2012; 120: 25-36.

[32] ESA Introducing Sentinel-2. Available online: http://www.esa.int/ Applications/Observing_the_Earth/Copernicus/Sentinel-2/Introducing_Sen tinel-2. Accessed on [2015-12-17]

[33] Delegido J, Verrelst J, Alonso L, Moreno J. Evaluation of Sentinel-2 red-edge bands for empirical estimation of green LAI and Chlorophyll content. Sensors, 2011; 11: 7063-7081.

[34] Wang Y J, Qi Q, Liu Y. Unsupervised segmentation evaluation using area-weighted variance and Jeffries-Matusita distance for remote sensing images. Remote Sensing, 2018; 10: 1193. doi: 10.3390/rs10081193.

[35] Qiu B W, Fan Z L, Zhong M, Tang Z H, Chen C C, Wardlow B D, et al. A new approach for crop identification with wavelet variance and JM distance. Environmental monitoring and assessment, 2014, 186(11): 7929-7940.

[36] Wardlow B D, Egbert S L, Kastens J H. Analysis of time-series MODIS $250 \mathrm{~m}$ vegetation index data for crop classification in the US Central Great Plains. Remote Sens. Environ., 2007; 108: 290-310.

[37] Sonobe R, Tani H, Wang X F, Kobayashi N, Shimamura H. Random forest classification of crop type using multi-temporal TerraSAR-X dual-polarimetric data. Remote Sens. Lett., 2014; 5: 157-164.

[38] Cortes C, Vapnik V. Support-Vector Networks. Mach Learn., 1995; 20: 273-297.

[39] Mountrakis G, Im J, Ogole C. Support vector machines in remote sensing: A review. ISPRS J. Photogramm. Remote Sens., 2011; 66: 247-259.

[40] Naghibi S A, Ahmadi K, Daneshi A. Application of support vector machine, random forest, and genetic algorithm optimized random forest models in groundwater potential mapping. Water Resour. Manag., 2017; 31: 2761-2775.

[41] Foody G M, Mathur A. The use of small training sets containing mixed pixels for accurate hard image classification: Training on mixed spectral responses for classification by a SVM. Remote Sens. Environ., 2006; 103(2): 179-189.

[42] Rumelhart D E, Hinton G E, Williams R J. Learning representations by back propagating errors. Nature, 1986; 323: 533-536.

[43] Li L Y, Chen Y, Xu T B, Liu R, Shi K F, Huang C. Super-resolution mapping of wetland inundation from remote sensing imagery based on integration of back-propagation neural network and genetic algorithm. Remote Sens. Environ., 2015; 164: 142-154.

[44] Chan J C, Paelinckx D. Evaluation of random forest and adaboost tree-based ensemble classification and spectral band selection for ecotope mapping using airborne hyperspectral imagery. Remote Sens. Environ., 2008; 112: 2999-3011.

[45] Zhang L, Liu Z, Liu D Y, Xiong Q, Yang N, Ren T W, et al. Crop mapping based on historical samples and new training samples generation in Heilongiiang Province, China. Sustainability, 2019; 11: 5052. doi: 10.3390/su11185052.

[46] Rodriguez-Galiano V F, Chica-Olmo M, Abarca-Hernandez F, Atkinson P M, Jeganathan C. Random Forest classification of Mediterranean land cover using multi-seasonal imagery and multi-seasonal texture. Remote Sens. Environ., 2012; 121: 93-107.

[47] Breiman L. Random Forests. Mach Learn., 2001; 45: 5-32.

[48] Immitzer M, Atzberger C, Koukal T. Tree species classification with random forest using very high spatial resolution 8-band WorldView-2 satellite data. Remote Sens., 2012; 4: 2661-2693.

[49] Díaz-Uriarte R, De Andres S A. Gene selection and classification of microarray data using random forest. BMC Bioinformatics, 2006; 7: 3 . doi: 10.1186/1471-2105-7-3.

[50] Congalton R, Green K. Assessing the accuracy of remotely sensed data. Boca Raton: CRC Press, 2019; 200p

[51] Congalton R G. A review of assessing the accuracy of classifications of remotely sensed data. Remote Sens. Environ., 1991; 37: 35-46.

[52] Liu J, Wang L M, Yang F G, Yao B M, Yang L B. Recognition ability of red edge and short wave infrared spectrum on maize and soybean. Chinese Agricultural Science Bulletin, 2018; 34: 120-129. (in Chinese)

[53] Huete A R, Didan K, Miura T, Rodriguez E P, Gao X, Ferreira L G. Overview of the radiometric and biophysical performance of the MODIS vegetation indices. Remote Sens. Environ., 2002; 83: 195-213.

[54] Huete A R. A soil-adjusted vegetation index (SAVI). Remote Sens. Environ., 1988; 25: 295-309.

[55] Dash J,. Curran P. Evaluation of the MERIS terrestrial chlorophyll index (MTCI). Adv. Space Res., 2007; 39: 100-104.

[56] Guyot G, Baret F, Major D. High spectral resolution: determination of spectral shifts between the red and the near infrared. Int. Arch. Photogramm. Remote Sens., 1988; 11: 750-760.

[57] Rouse J W, Hass R H, Scheel J A, Deering D W. Monitoring vegetation systems in the Great Plain with ERTS. In: Proceedings of the 3rd Earth Resources Technology Satellite-1 Symposium, Washington, DC, USA, 1973; pp. 309-317.

[58] Gitelson A A, Merzlyak M. Remote estimation of chlorophyll content in higher plant leaves. Int. J. Remote Sens., 1997; 18: 2691-2697.

[59] Mcfeeters S K. The use of the Normalized Difference Water Index (NDWI) in the delineation of open water features. Int. J. Remote Sens., 1996; 17: 1425-1432.

[60] Zha Y, Ni S X, Yang S. An effective approach to automatically extract urban land-use from TM imagery. J. Remote Sens., 2003; 7: 38-40. (in Chinese)

[61] Zheng Y, Zhang M, Zhang X, Zeng H W, Wu B F. Mapping winter wheat biomass and yield using time series data blended from PROBA-V 100- and 300-m S1 products. Remote Sens., 2016; 8: 824 . doi: $10.3390 / \mathrm{rs} 8100824$.

[62] Immitzer M, Vuolo F, Atzberger C. First experience with Sentinel-2 data for crop and tree species classifications in central Europe. Remote Sens., 2016; 8: 166 . doi: 10.3390/rs8030166.

[63] Genuer R, Poggi J, Tuleau-Malot C. Variable selection using random forests. Pattern Recognit. Lett., 2010; 31: 2225-2236.

[64] Kirar J S, Agrawal R K. Relevant frequency band selection using Sequential forward feature selection for motor imagery brain computer interfaces. 2018 IEEE Symposium Series on Computational Intelligence (SSCI), Bangalore: IEEE, 2018; pp.52-59. 